\title{
A FUNCTIONAL VIEW REVEALS SUBSTANTIAL PREDICTABILITY OF POLLINATOR-MEDIATED SELECTION
}

\author{
Øystein H. Opedal \\ Department of Biology, Lund University, Sölvegatan 37, 22362 Lund, Sweden
}

Journal of Pollination Ecology, 30(21), 2021, pp 273-288

DOI: $10.26786 / 1920-$

$7603(2021) 673$

Received 26 October 2021, accepted 10 November 2021 *Corresponding author: oystein.opedal@biol.lu.se

\begin{abstract}
A predictive understanding of adaptation to changing environments hinges on a mechanistic understanding of the extent and causes of variation in natural selection. Estimating variation in selection is difficult due to the complex relationships between phenotypic traits and fitness, and the uncertainty associated with individual selection estimates. Plant-pollinator interactions provide ideal systems for understanding variation in selection and its predictability, because both the selective agents (pollinators) and the process linking phenotypes to fitness (pollination) are generally known. Through examples from the pollination literature, I discuss how explicit consideration of the functional mechanisms underlying trait-performance relationships can clarify the relationship between traits and fitness, and how variation in the ecological context that generates selection can help disentangle biologically important variation in selection from sampling variation. I then evaluate the predictability of variation in pollinatormediated selection through a survey, reanalysis, and synthesis of results from the literature. The synthesis demonstrates that pollinator-mediated selection often varies substantially among trait functional groups, as well as in time and space. Covariance between patterns of selection and ecological variables provides additional support for the biological importance of observed selection, but the detection of such covariance depends on careful choice of relevant predictor variables as well as consideration of quantitative measurements and their meaning, an aspect often neglected in selection studies.
\end{abstract}

Keywords-Adaptive landscape, causal modelling, path analysis, phenotypic selection, pollinator-mediated selection, selection gradient

\section{INTRODUCTION}

Natural selection is the primary mechanism by which populations adapt to their environments. Because selection is an ecological process, it is expected to covary in predictable ways with the environments that populations currently experience. For example, the important role of animal pollinators in driving plant evolution (Darwin 1862; Grant \& Grant 1965; Stebbins 1974) suggests that selection on phenotypic traits functionally involved in the pollination process are likely to covary with variation in pollinator assemblages. Knowledge of such covariation may allow us to forecast patterns of selection following environmental changes, such as a pollinator decline or other change in the local pollinator community.
Since field measurements of selection were operationalized by Lande, Arnold and Wade (Lande \& Arnold 1983; Arnold \& Wade 1984b; Arnold \& Wade 1984a), thousands of selection estimates have accumulated in the literature, followed by quantitative syntheses and metaanalyses (Kingsolver et al. 2001; Harder \& Johnson 2009; Siepielski et al. 2009; Siepielski et al. 2013; Caruso et al. 2017; Siepielski et al. 2017; Caruso et al. 2019). In a global meta-analysis, Siepielski et al. (2017) identified variation in precipitation patterns as a major driver of variation in selection. Although such broad-scale patterns are encouraging, several authors have pointed out that a predictive understanding of variation in selection hinges on a functional understanding of the mechanisms linking phenotypes to fitness (e.g. Arnold 1983; Endler 1986; Wade \& Kalisz 1990; 
Conner 1996; Walker 2007; MacColl 2011). Indeed, viewing selection through a functional lens may facilitate the identification of ecological correlates of selection, thus improving predictability (Herrera et al. 2006; MacColl 2011; Albertsen et al. 2021).

By taking 'a functional view' I do not mean to indicate that certain traits are more functional than are others. What I mean is that understanding phenotypic selection requires explicit consideration of the (hypothesized) function of the studied traits in a particular context such as pollination. I will refer to functional classes of traits including those involved in pollinator attraction (floral advertisements and rewards), reproductive assurance (e.g. herkogamy), and flower-pollinator fit. The latter class comprises those traits that interact functionally with phenotypic traits of pollinators in determining the efficiency of pollen transfer to and from the bodies of pollinators. Examples include the length of corolla tubes interacting with pollinator tongue length (Nilsson 1988), corolla-tube width interacting with the beak size of hummingbirds (Campbell et al. 1991), and reward-stigma distances interacting with the body length of bees (Armbruster 1990). Because these different trait classes serve different functions, it is both important and possible to separate distinct paths linking phenotype to fitness and thus gain a more complete understanding of the selective process (Conner 1996; Bolstad et al. 2010; PérezBarrales et al. 2013).

Here, I discuss how the necessary kinds of knowledge and data can be obtained and combined into a more predictive understanding of natural selection. I will argue that the predictability of variation in selection can be improved by leveraging a combination of (i) functional knowledge of trait-performance-fitness relationships, (ii) quantitative interpretation of selection estimates, and (iii) explicit consideration of spatiotemporal variation in ecological variables relevant to the focal component of selection. Although each of these components have been considered in individual studies, they are yet to be applied jointly and systematically across diverse systems. I focus my discussion and analysis on pollinator-mediated selection on flowers, and explicitly evaluate the current level of predictability through a literature survey, reanalysis, and synthesis of existing results.

\section{ISOLATING TRAIT-PERFORMANCE-FITNESS RELATION- SHIPS AND CAUSAL COMPONENTS OF SELECTION}

Many factors can mediate trait-fitness relationships, and a major challenge in selection studies is therefore to separate the focal component of selection (e.g. pollinator-mediated selection) from other sources of variation in fitness. Doing so requires a functional understanding of how variation in specific traits leads to variation in performance and ultimately fitness. This idea was elegantly illustrated by Arnold (1983), who recognized that the process of selection can be decomposed into a relationship between phenotype and performance (e.g. how head morphology affects the swallowing performance of snakes), and a relationship between performance and fitness. In pollination studies, pollinator attraction as well as pollen pick-up from, and deposition on, pollinator bodies can be seen as performance, which in turn affects fitness as quantified by seed set or siring success through pollen export (e.g. Wilson 1995a; Armbruster et al. 2005). A major advantage of pollination systems in selection studies is that both the selective agents (pollinators) and the causal mechanisms linking specific phenotypic traits to fitness (pollination) often are known or can be readily hypothesized. Furthermore, flowers are highly amenable to experimental manipulations designed to isolate the effects of pollinators on performance and fitness and the functional roles of individual traits in mediating these trait-performance-fitness relationships. Although the pollination-related component of fitness may differ from lifetime fitness, focusing on a single causal component facilitates the identification of relevant ecological covariates, as discussed below.

Experimental floral manipulations have been widely used to test hypothesized traitperformance relationships (see review in Harder \& Johnson 2009). Examples of this approach include experimental reduction of floral advertisement to show that pollinators choose blossoms based on visual cues (Andersson 1996; Armbruster et al. 2005), manipulation of nectar availability to demonstrate effects on pollinator foraging behaviour (Mitchell 1993), and manipulation of 
flower-pollinator fit traits to test functional hypotheses about the mechanics of pollen transfer (Nilsson 1988; Campbell et al. 1996; Johnson \& Steiner 1997; Cresswell 2000; Conner 2003; Aigner 2005; Muchhala \& Thomson 2009). A few studies have manipulated multiple traits, thus assessing possible effects of trait combinations on performance (i.e. correlational selection; Castellanos et al. 2004; Campbell 2009; Sletvold \& Ågren 2011; Campbell et al. 2014). These experiments provide exactly the kinds of traitperformance relationships needed to understand the mechanisms of natural selection.

Choosing relevant focal traits and establishing their links to performance is an important first step towards a more predictive understanding of selection. The next step is to use this functional understanding to isolate and quantify the focal component of selection (e.g. pollinator-mediated selection) in terms of selection gradients (Lande \& Arnold 1983). One powerful method for doing so is to supplement stigmatic pollen loads to the point where seed set is no longer limited by pollen arrival. Because variation in fitness (in terms of seed production) will no longer depend on variation in pollinator attraction or the efficiency of pollen transfer, any selection detected on handpollinated flowers must have a different cause. One clear pattern emerging from studies implementing this method (e.g. Totland et al. 1998; Sandring \& Ågren 2009; Parachnowitsch \& Kessler 2010; Sletvold \& Ågren 2010; Chapurlat et al. 2015; Trunschke et al. 2017; Eisen et al. 2020) is that selection on size- and fecundity-related traits such as plant height and especially flower display size (number of flowers) is often detected among handpollinated plants ( $\beta$ supplemental $>0$, see review in Sletvold 2019). This suggests that selection for overall 'vigour' is mediated in part by factors other than pollination, and nicely illustrates the power of this experimental approach in 'removing' nonpollinator-mediated selection. In contrast, any selection on traits directly involved in pollen transfer (flower-pollinator fit traits and flower size in some systems) is typically found to be mediated by pollinators (Sletvold \& Ågren 2014; Chapurlat et al. 2015; Trunschke et al. 2017; and see Appendix S1). This illustrates some important and predictable differences among traits serving different functions and suggests that selection on fit traits detected in studies considering open- pollinated plants only may at least provisionally be interpreted as pollinator-mediated.

In his paper Correlation and Causation, Sewall Wright (1921) argues that causality can in some cases be inferred by interpreting observed relationships in light of prior knowledge of the causal relations between variables. Causal modelling provides a particularly useful tool for studies of plant-pollinator interactions and pollinator-mediated selection, precisely because the functional roles of traits often follow from knowledge of the natural history of the study system and the mechanics of pollen transfer as ascertained by the kinds of experiments reviewed above. Path analysis and related methods (e.g. structural-equation modelling, see Shipley 2016) have been widely used to study phenotypic selection on floral and other pollination-related plant traits (e.g. Schemske \& Horvitz 1988; Kingsolver \& Schemske 1991; Stanton et al. 1991; Mitchell 1994; Scheiner et al. 2000; Hansen \& Totland 2006; Parachnowitsch \& Caruso 2008; Gómez et al. 2009; Bartkowska \& Johnston 2012; La Rosa \& Conner 2017). A classic example is the study of Schemske and Horvitz (1988), who studied the direct and indirect effects of pollinators and several other biotic interactors on seed set in Calathea ovandensis. On the pollination side, they found that pollinator taxa responded differently to variation in flower size, and that variation in visitation rates of each pollinator had different effects on seed set. Importantly, they were able to combine this observation with data on the efficiency of each pollinator species (Schemske \& Horvitz 1984), thus providing a mechanistic understanding of the observed patterns. Finally, they used these insights to interpret variation in selection among years as the assemblage of pollinators varied (Schemske \& Horvitz 1989). The latter point is crucial because it illustrates how combining causal modelling with a mechanistic understanding of trait-performance relationships allows making predictions not only about how a change in the environment (e.g. the composition of the pollinator assemblage) affects selection, but through which pathways and traits these changes occur.

A particularly powerful use of causal modelling in selection studies is to build fitness functions linking specific phenotypic traits to 


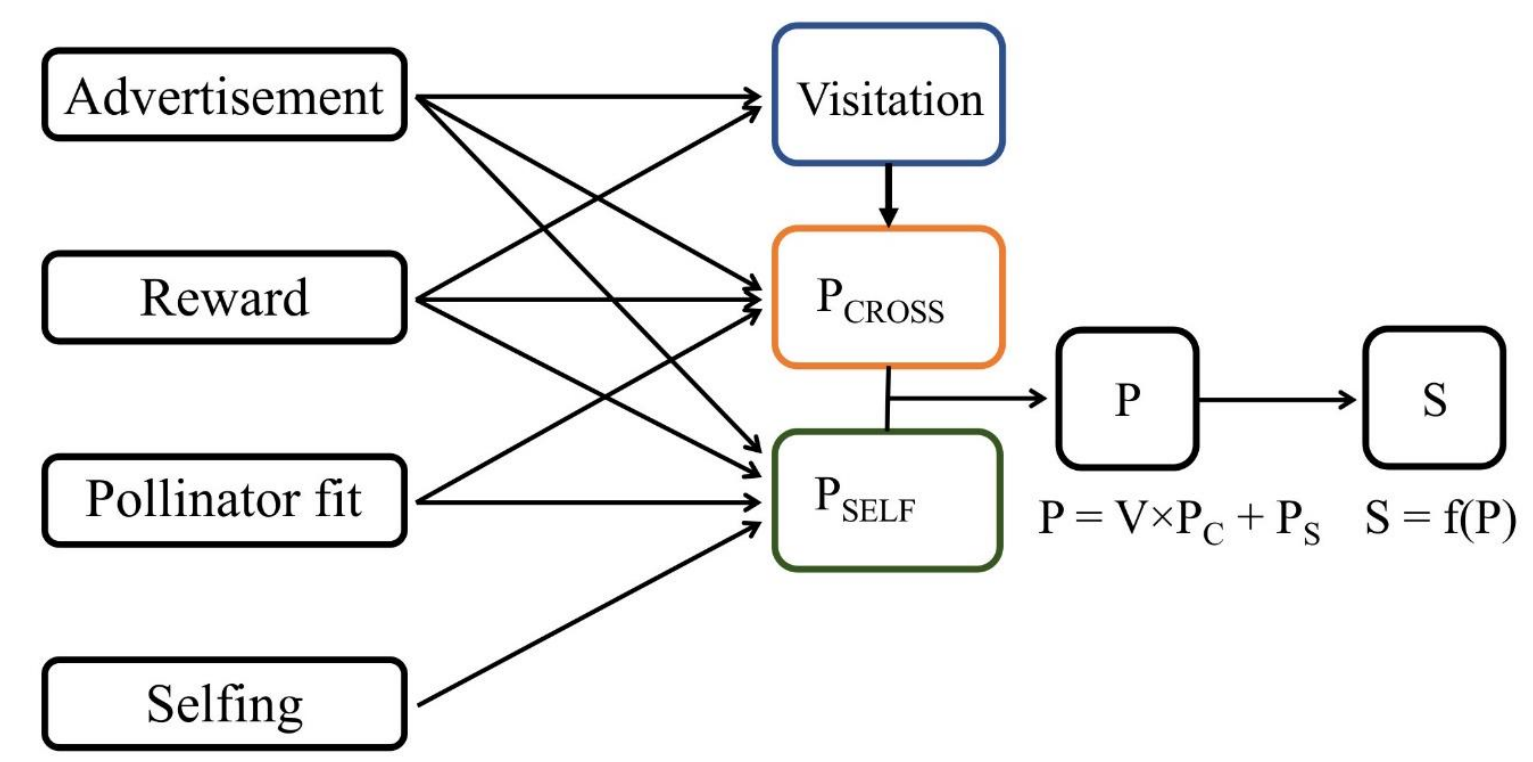

Figure 1. Graphical representation of a path-analytical fitness function linking pollination traits to female reproductive performance (predicted number of seeds produced, $S$ ). The number of seeds produced is an asymptotic function of the number of pollen grains $(P)$ deposited onto stigmas through cross- $\left(P_{\text {CROSS }}\right)$ and self-pollination $\left(P_{\text {SELF }}\right)$. Cross-pollen arrival is conditional on pollinator visitation. Pollen load can increase through attraction of pollinators responding to advertisement or reward traits, and the efficiency of pollen transfer is determined by the mechanical fit of the pollinator to the flower. The rate of selfpollination is also determined by traits affecting within-flower pollen transfer. This approach isolates the process of pollination from other sources of variation in fitness by defining seed set as a direct function of pollen deposition. Selection gradients can be obtained by regressing the predicted relative fitness values on the traits.

fitness via intermediate performance components. Biologically, the fitness-function approach takes advantage of the necessary sequence of events leading to successful seed production, and the knowledge about which traits are functionally involved in each step (Fig. 1). Seed production depends on pollen deposition onto stigmas, which in turn depends on pollinator attraction through advertisements and rewards as well as pollen pickup from pollinators through precise fit of flowers to pollinators. In self-compatible species, selection can also act through reproductiveassurance mechanisms such as reduced herkogamy (anther-stigma separation). By decomposing the selective process into these components, more complete insights can be gained compared to the direct estimation of selection gradients as the regression of observed relative fitness on the traits. For example, both Bolstad et al. (2010) and Pérez-Barrales et al. (2013) applied a fitness-function approach to ask whether pollinators base their foraging decisions on floral advertisements or on direct assessment of reward availability and came to opposite conclusions.
Although such differences will not necessarily affect the overall strength or patterns of selection through seed set, the explicit consideration of factors affecting pollinator foraging decisions and thus the links between phenotypic traits and pollination success (performance) provides a deeper understanding of the selective process and is likely to improve the predictability of selection.

The fitness-function approach also has several technical advantages in that it is highly flexible in terms of statistical link functions (Shaw et al. 2008), and that it allows reducing the well-known issue of spurious correlations arising from environmental covariance between traits and fitness (Rausher 1992; Bolstad et al. 2010).

\section{HOW STRONG AND HOW VARIABLE IS SELECTION ON POLLINATION TRAITS?}

Considering the functional relationships between phenotypic traits, performance and fitness allows us to understand spatiotemporal variation in the shape of fitness surfaces (Arnold 


\section{Box 1. Measuring the strength and variation of selection}

As regression slopes of relative fitness on a set of phenotypic traits (Lande \& Arnold 1983), selection gradients have units of one per original trait unit and will vary among traits of different mean sizes, variances, measurement dimensions, and scale types. Therefore, selection gradients are normally scaled against the phenotypic standard deviation, thus obtaining variance-standardized selection gradients ( $\beta_{\sigma}=\beta \sigma$, where $\sigma$ is the trait standard deviation) interpretable as the change in relative fitness per standard deviation change in the trait (also referred to as selection intensities i; Lande \& Arnold 1983; Hereford et al. 2004). Alternatively, selection gradients can be scaled against the trait mean, yielding mean-standardized selection gradients $\left(\beta_{\mu}=\beta \mu\right.$, where $\mu$ is the trait mean) interpretable as the change in relative fitness per proportional (percent) change in the trait (van Tienderen 2000; Hereford et al. 2004; Matsumura et al. 2012; De Lisle \& Svensson 2017). This yields a useful benchmark for judging the strength of selection, because a mean-standardized selection gradient of $100 \%$ means that selection is as strong as selection on relative fitness itself, as a trait (Hereford et al. 2004).

Writing the ratio of the variance- and mean-standardized selection gradients as $\beta_{\sigma} / \beta_{\mu}=\beta \sigma / \beta \mu=\sigma \mu^{-1}$ clarifies that, whenever traits differ in proportional variation $\left(\mathrm{CV}=\sigma \mu^{-1}\right)$, the ratio of the selection gradients subject to the two kinds of scaling will change. The choice of standardization can therefore change the ranking of traits in terms of selection strength, and thus the conclusions of comparative studies (Hereford et al. 2004).

A second challenge in the comparative study of selection is how to estimate variation in selection in space and time. Selection-gradient estimates are associated with substantial statistical uncertainty which needs to be accounted for when assessing variation among years, populations, and species (Morrissey \& Hadfield 2012; Morrissey 2016). For individual studies comparing multiple populations or years, Albertsen et al. (2021) have recently proposed to measure the among-study variance as

$$
\sigma_{\beta}^{c}=\sqrt{\sigma_{\beta}^{2}-\overline{\mathrm{SE}_{\beta}^{2}}}
$$

where $\sigma^{2} \beta$ is the variance of the selection-gradient estimates among studies, and $\mathrm{SE}^{2} \beta$ is the sampling variance of each selection-gradient estimate. For mean-standardized selection gradients, this measure can be interpreted as the mean dispersion of the selection estimates in units of the strength of selection on fitness itself.

1983; Walker 2007). Evolutionary interpretation of such variation must necessarily also be based on the strength of selection and its variation among traits, years, and populations (Box 1). Assessing such variation is central to studies of selection mosaics (geographic variation in selection due e.g. to variation in species interactions; see Thompson 2005), including tests of how selection on flowers covaries with variation in pollinator communities and phenotypes (Herrera et al. 2006).

All existing quantitative surveys and metaanalyses of selection on floral traits (Harder \& Johnson 2009; Parachnowitsch \& Kessler 2010; Bartkowska \& Johnston 2015; Caruso et al. 2019), and the vast majority of case studies, have reported variance-standardized but not mean-standardized selection gradients (Box 1). Because variancestandardized selection gradients, unlike meanstandardized gradients, lacks a natural benchmark for evaluating the strength of selection (Hereford et al. 2004), it is unclear exactly how strong selection on pollination traits typically is.
Similarly, few studies have considered the magnitude of variation in space and time relative to the sampling variance in the gradients. To assess these unanswered questions, I compiled selection estimates and summary statistics from a sample of selection studies with temporal or spatial replication, and where the necessary summary statistics and measures of sampling uncertainty (standard errors or confidence intervals) were available (see Appendix S1 for further details). I selected studies based on a comprehensive review of the literature during the preparation of this paper but did not perform systematic database searches. The included studies focused on plantpollinator interactions or at least phenotypic selection on 'pollination traits', which I defined as floral traits as well as plant-level traits perceived to be important for plant-pollinator interactions, such as plant size (height) and flowering phenology. I included both studies considering open-pollinated plants only (thus estimating net selection), and those explicitly aiming to isolate pollinatormediated selection. For each study, I included 
those estimates perceived by the original investigators to be the best estimate of pollinatormediated selection.

I assessed the typical strength of selection by computing the median absolute value of the selection gradients (i.e. median $\left|\beta_{\mu}\right|$ ). To account for the upward bias in mean magnitudes due to estimation error in the individual selection estimates, I corrected each absolute selection gradient by subtracting the expected bias computed using equations 7 and 8 in Hereford et al. (2004). To assess and compare variation in selection in space (among sites within a year) and time (among years at a site), I computed $\sigma_{\beta}^{c}$ (Box 1) for each study, separately for temporal and spatial variation.

The survey illustrates several important points about the strength and variation in selection on traits functionally related to pollination. First, selection on pollination traits is often strong (median $\left|\beta_{\mu}\right|=0.51$, bias-corrected median $\left|\beta_{\mu}\right|=$ $0.40, N=396)$, and can be very strong $\left(\beta_{\mu}>1\right)$ in specific cases (Fig. 2). Second, selection estimates are usually associated with considerable uncertainty. The median magnitude (strength) of selection of $51 \%$ of the strength of selection on fitness is only a little larger than the median standard error of the estimates $( \pm 37.4 \%)$. Consequently, in any given study, most selectiongradient estimates are statistically non-significant. Treating $\left|\beta_{\mu}\right|>1.96 \times \mathrm{SE}\left(\beta_{\mu}\right)$ as a criterion for statistical significance, $28.9 \%$ of the estimates would be declared significant. Third, variation in selection in space and time can be substantial even after accounting for sampling error. The observed variation in selection exceeded the mean sampling variance in $52.9 \%$ of the cases for temporal variation $(N=51)$, and $46.3 \%$ of the cases for spatial variation $(N=54$, Fig. 3$)$. For those cases where the observed variation in selection exceeded the mean sampling variance, the median dispersion of the estimates $\left(\sigma_{\beta \mu}^{\mathrm{c}}\right)$ was $25.2 \%$ for temporal variation, and $26.4 \%$ for spatial variation.

The median strength as well as magnitude of variation in selection varied among trait functional classes. Thus, substantial predictability arises from knowledge about trait functions. For example, compared to other pollination traits, selection on flower-pollinator fit traits tended to be stronger
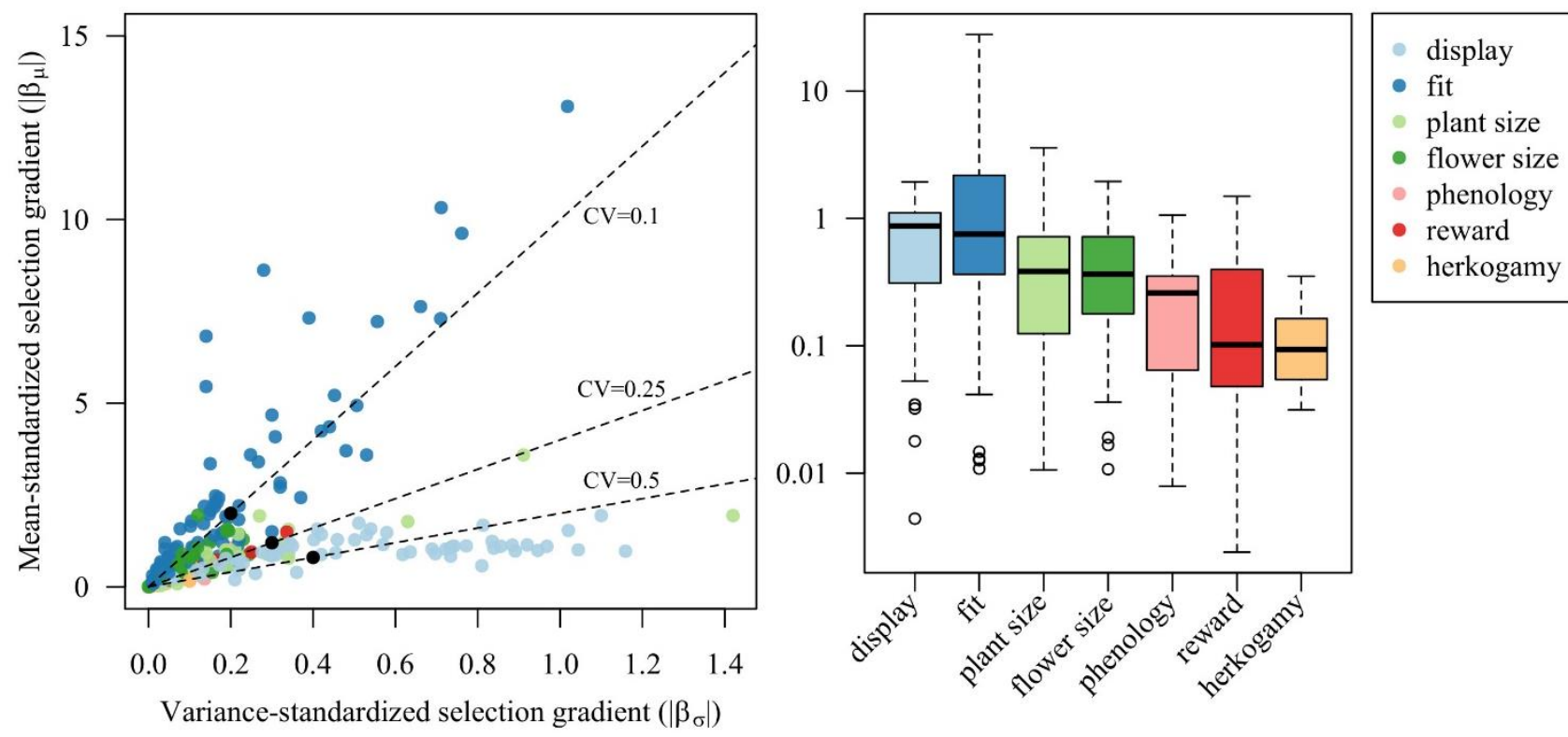

Figure 2. (A) Scatterplot of absolute mean-standardized and variance-standardized multivariate selection gradients on plant traits, with colours representing distinct trait functional groups. Variance-standardized gradients describe the change in relative fitness per standard deviation change in the trait and mean-standardized gradients describe the change in relative fitness per change in the trait mean, with a value of 1 corresponding to the strength of selection on relative fitness as a trait. Dotted lines illustrate how the relationship between variance-standardized and mean-standardized gradients vary with the coefficient of variation (CV) of the trait. The black dots represent three hypothetical traits which rank opposite for the two measures of selection strength, with variance-standardized gradients of $0.2,0.3$ and 0.4 corresponding to mean-standardized gradients of 2 , 1.2, and 0.8. (B) Distribution of absolute mean-standardized selection gradients across trait functional groups. 
Temporal variation
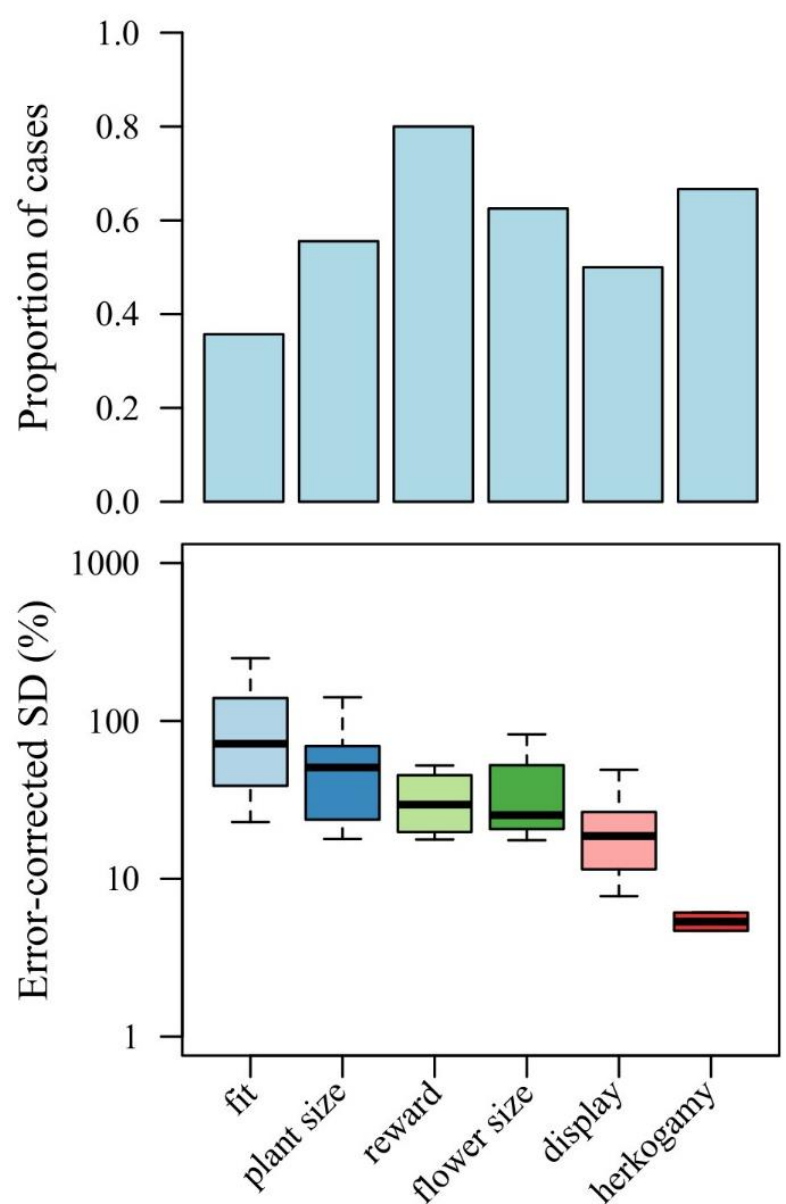

Spatial variation
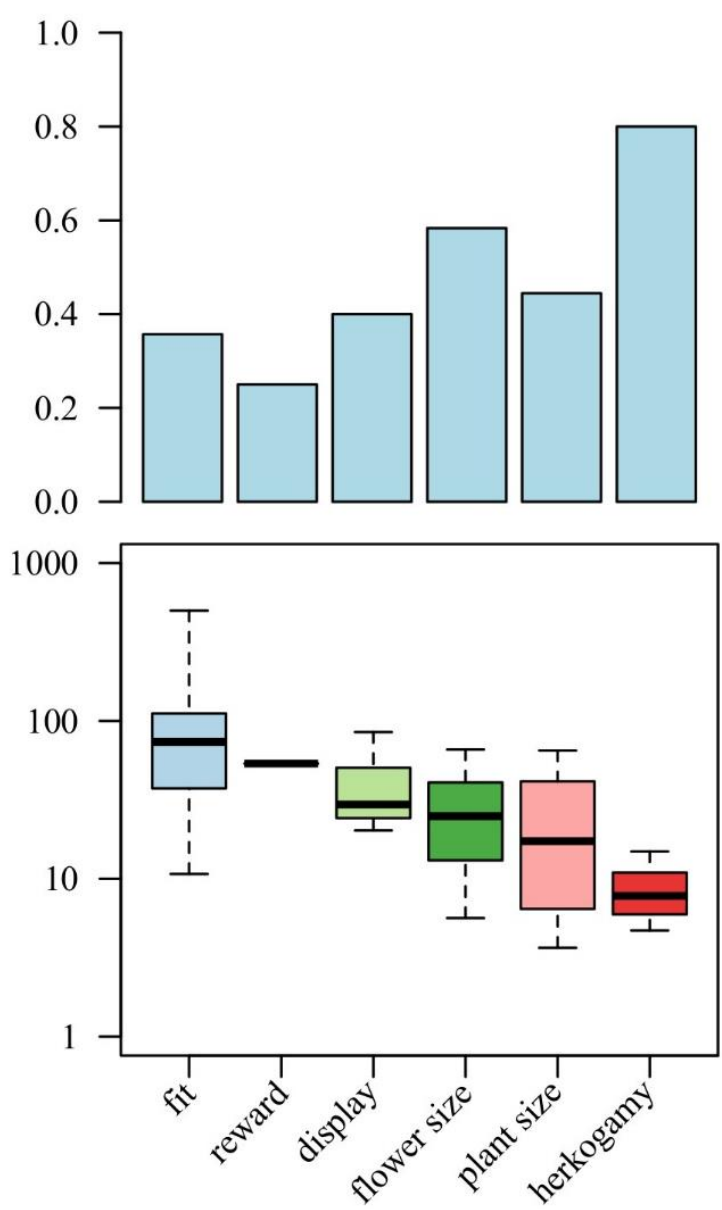

Figure 3. Patterns of temporal (among years for a site) and spatial (among sites within a year) variation in phenotypic selection on pollination traits. The barplots indicate the proportion of cases where variation in selection remain after accounting for sampling variance, and the boxplots give the distribution of error-corrected standard deviations of selection gradients for those cases where variation was detected. The error-corrected standard deviations can be interpreted as the average difference in selection among years (for temporal variation) or sites (for spatial variation). A mean-standardized selection gradient of $100 \%$ means that selection is as strong as selection on fitness as a trait.

(Fig. 2), and also more variable in space and time in those cases where selection varied detectably (Fig. 3).

The relationship between mean- and variancestandardized selection gradients depends on the phenotypic coefficient of variation (Box 1). In the case of flowers, it is particularly interesting to note that fit traits tend to have lower proportional variances than other traits, a pattern interpreted as consistent with (historical) pollinator-mediated stabilizing selection on these traits (Cresswell 1998; Opedal 2019). This pattern has important consequences for interpreting patterns of selection because the mean-scaled gradient corresponding to a given variance-scaled gradient will tend to be higher for fit traits than for other traits (Fig. 2). Thus, it is not surprising to find cases where fit traits are under stronger selection relative to selection on fitness, but weaker selection in units of standard deviations (Appendix S1) Importantly, this difference is not just a statistical curiosity, but results from the interplay between trait function and the evolution of variational properties.

Finally, an important insight from the literature survey is that while selection estimates in a single population in a single year are expected, on average, to be statistically non-significant, most studies detect biologically highly significant variation among populations, years, or species. By 
linking this variation to variation in ecological context, we can move toward a more predictive understanding of natural selection and population responses to environmental changes.

\section{LINKING VARIATION IN SELECTION TO ECOLOGICAL CONTEXT}

In populations that are well adapted to their environment, we do not (necessarily) expect strong directional selection. As illustrated by the literature survey, these cases may be frequent, and studies failing to detect selection may be fully in line with predictions and may be as important and interesting as those detecting strong selection. The crucial data needed to separate a lack of detectable selection due to e.g. low statistical power or improper choice of focal traits or fitness components from 'true' lack of selection are those indicating whether pollinator-mediated selection is expected to occur under those ecological conditions in which selection was measured. Even stronger support comes from studies that are replicated in space and/or time, and that demonstrate that selection covaries with relevant ecological variables (Herrera et al. 2006). In the following sections I review some of the substantial progress in this area since the benefits of the geographic comparative approach to studies of pollinator-mediated selection was pointed out by Herrera et al. (2006).

The best studied environment-selection relationship in the plant literature is that between pollen limitation (or population-mean pollination success), opportunity for selection, and strength of selection (Wilson 1995b; Ashman \& Morgan 2004; Benkman 2013; Vanhoenacker et al. 2013; Sletvold \& Ågren 2014; Bartkowska \& Johnston 2015; Sletvold \& Ågren 2016; Emel et al. 2017; Trunschke et al. 2017; Albertsen et al. 2021). The emerging pattern is that, when pollination is unreliable (i.e. low average rates of pollen arrival onto stigmas leading to severe pollen limitation), both the mean selection strength and the variance among studies and traits increases (Ashman \& Morgan 2004; Sletvold \& Ågren 2014; Bartkowska \& Johnston 2015; Trunschke et al. 2017; Albertsen et al. 2021). In other words, when pollination is unreliable the opportunity for selection increases, and this may translate into selection on one or more traits. Population-level pollination reliability is thus a strong predictor of variation in selection, but additional factors need to be considered to understand when selection occurs in unreliable pollination environments, and on which traits selection acts.

How variation in population-level pollination reliability affects selection on flower phenotypes can be expected to differ depending on whether low pollination reliability results from low visitation rates or poor flower-pollinator fit. In the former case, we may expect selection to act primarily through mechanisms of pollinator attraction (Vanhoenacker et al. 2013), such as increases in reward production or advertisements (Fig. 4a), or autonomous self-pollination, such as reduced anther-stigma separation within flowers (Fig. 4b; Moeller \& Geber 2005; Bodbyl Roels \& Kelly 2011; Opedal et al. 2017). When low pollination reliability results from poor flowerpollinator fit, selection for greater pollen arrival may act both through pollinator attraction and through the efficiency of pollen transfer. Positive relationships across populations and species between relevant measures of flower and pollinator size and shape represent classic examples of adaptation (Armbruster 1988; Steiner \& Whitehead 1990; Anderson \& Johnson 2009; Anderson et al. 2010; Boberg et al. 2014). If plants evolve to 'fit' their principal pollinators, we expect patterns of selection to change in the event of a change in the functional traits of floral visitors. A simple case is the replacement of the current principal pollinator (i.e. the most abundant and/or efficient pollinator) by another, in which case we expect immediate changes in patterns of selection. A recent example occurred on the island of Dominica in the Lesser Antilles following hurricane 'Maria' in 2017. The hummingbirdpollinated Heliconia wagneriana experienced a change in the mean beak length and shape of its pollinators, which led to a change in the fit of flowers to pollinators, and a change from weakly positive to strongly negative selection on corolla tube length, an important trait affecting flowerpollinator fit (Temeles \& Bishop 2019). Similarly, Mackin et al. (2021) recently detected clear changes in patterns of selection on corolla dimensions in the introduced range of Digitalis purpurea in the neotropics, where hummingbirds are added to the pollinator assemblage. 
(A)

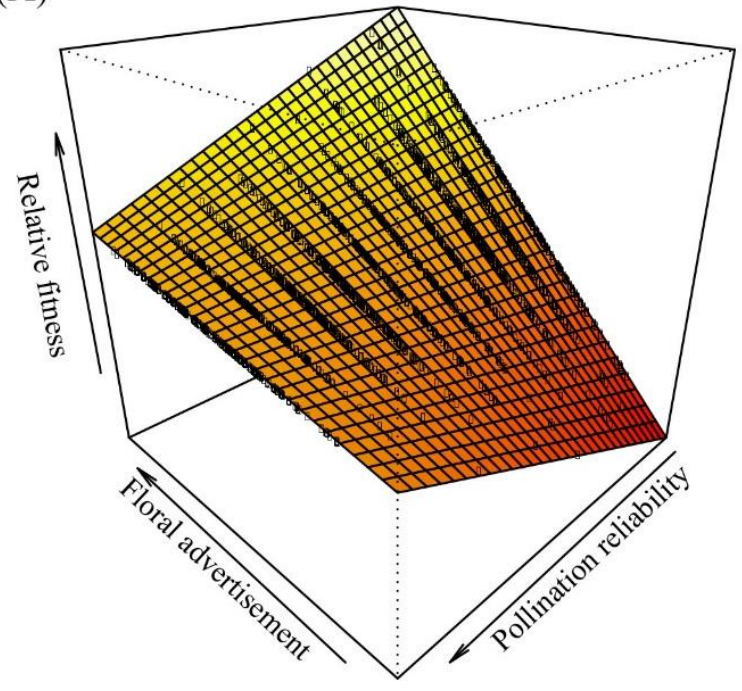

(C)

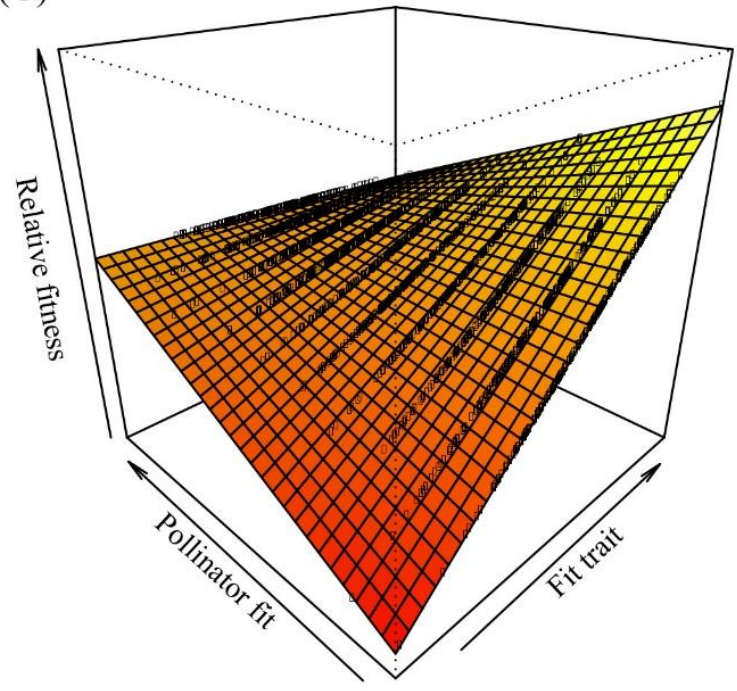

(B)

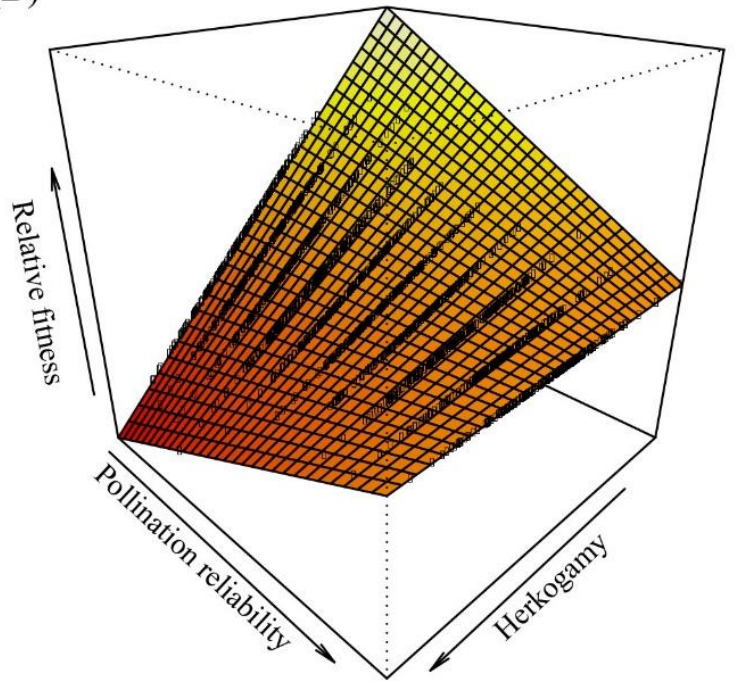

(D)

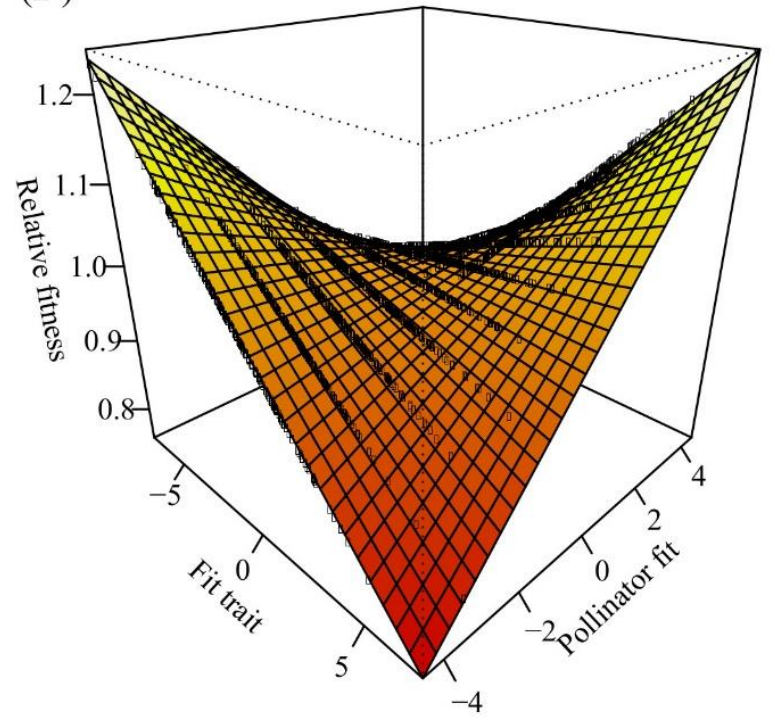

Figure 4. Examples of how the linear component of fitness surfaces for floral traits involved in pollinator attraction, selfpollination and flower-pollinator fit may be expected to covary with ecological variables (pollination reliability and correspondence between pollinator and floral traits ('pollinator fit'). In all panels, the rows of black symbols indicate the trait distribution of 10 hypothetical populations. With decreasing population-level pollination reliability we expect greater opportunity for selection and stronger positive directional selection on floral advertisement $(A)$ and/or stronger negative selection on herkogamy and other traits mediating self-pollination (B). Selection on pollinator-fit traits (e.g. reward-stigma distances, spur length) is expected to covary with population-mean flower pollinator fit (e.g. pollinator size - fit trait), but details will vary across systems. In (C), selection on the fit trait occurs at poor flower-pollinator fit but tends to zero as fit improves. In (D), selection on the fit trait is positive when the pollinator trait is larger than the fit trait (positive values), negative when the pollinator trait is smaller than the fit trait (negative values), and no directional selection occurs when the fit is optimal.

Details of how selection on flower-pollinator fit traits covaries with flower-pollinator fit are expected to vary across systems. In some cases, we expect mismatch between relevant pollinator and floral traits to lead to selection on the floral trait primarily when the mismatch occurs in a specific direction (Fig. 4c). Examples include species where pollinators insert their tongues into elongated corolla tubes or nectar spurs, where we expect positive selection on the fit trait when the 
pollinator's tongue is too long (e.g. Maad 2000; Alexandersson \& Johnson 2002; but see Ellis \& Johnson 2010). In other cases, pollen transfer may be most efficient at a specific size ratio of pollinators and fit traits, so that any deviation from the optimum will lead to directional selection towards the optimum (Fig. 4d). Importantly, in these cases we expect selection on fit traits to change direction depending on whether floral visitors are too large or too small.

HOW VARIATION IN POLLINATOR ASSEMBLAGES AFFECT SELECTION ON FLOWER-POLLINATOR FIT TRAITS

As a concrete example of how knowledge about trait function and ecological context can be combined into predictions of patterns of selection, I will consider in detail how selection on flowerpollinator fit traits vary across populations or years with different pollinators or pollinator phenotypes. Many studies have assessed such variation (Appendix 2: Table S1), and the literature survey suggested that variation is often substantial (Fig. 3). In perhaps the longest-running study of selection on floral traits, Campbell \& Powers (2015) assessed selection on Ipomopsis aggregata floral traits over 10 years, and combined the selection estimates with field observations of pollinators. In addition to demonstrating a strong influence of climate (snowmelt date) on selection, they found that selection on a flower-pollinator fit trait (corolla width) varied substantially among years $\left(\sigma_{\beta \mu}^{c}=109.3 \%\right)$ and turned more negative in those years where hawkmoths were important pollinators. Importantly, the interpretation of this finding was facilitated by previous observational and experimental work on pollinator-mediated selection on Ipomopsis floral traits. While there is good evidence that hummingbird-mediated selection on corolla width is related to the mechanical fit between the flowers and the birds' beaks (Campbell et al. 1991; Campbell et al. 1996), hawkmoth-mediated selection appears to relate in part to hawkmoth preference for flowers with narrowed corollas, and may thus not be due only to flower-pollinator fit (Campbell et al. 1997).

Variation in selection resulting from functionally distinct pollinators such as hummingbirds and hawkmoths (see also Gomez et al. 2008; Sahli \& Conner 2011; Kulbaba \& Worley 2012; Kulbaba \& Worley 2013) may occur in a predictable way and is well worth assessing.
However, it is uncertain whether such patterns can be extrapolated to pollinator functional types (Fenster et al. 2004) other than those for which data are available, and thus used for example to forecast patterns of selection following colonization of a novel environment where the original pollinators are lacking. In contrast, the accuracy of extrapolation may be higher in cases where pollinator functional type is unchanged, but the sizes of relevant functional traits differ (see Armbruster et al. 2011). One such case is the study of Albertsen et al. (2021), who used a fitnessfunction approach (Fig. 1) to estimate pollinationmediated selection on blossom traits in five Dalechampia scandens populations, three of which were studied over two years. By combining the selection estimates with data on pollinator assemblages (size distribution of bees visiting blossoms), they found that selection on glandstigma distance (a flower-pollinator fit trait) varied in space and time $\left(\sigma_{\beta \mu}^{c}=17.2 \%\right)$ and could be detected only in those cases where poor fit of pollinators to blossoms occurred in combination with low pollination reliability. In another recent example, Soteras et al. (2020) found that selection on the sexual organ sizes of the hawkmothpollinated Caesalpinia gilliesii tended to covary with the mean pollinator proboscis length, although patterns were heterogeneous across the several female fitness components considered and the among-site variation was less than the mean sampling variance of the gradients $\left(\sigma_{\beta \mu}^{\mathrm{c}}<0\right)$.

The optimum phenotype in terms of pollentransfer efficiency may not correspond to perfect matching between flower and pollinator fit traits. For example, Nattero et al. (2010) studied selection on corolla length and other fit traits in six populations of the hummingbird-pollinated Nicotiana glauca, and explicitly assessed covariation between selection and the mismatch between corolla length and the beak length of local pollinators. Interestingly, although the corolla tube was longer than the mean beak length in all populations, directional selection on corolla tube length varied substantially $\left(\sigma_{\beta \mu}^{c}=318.0 \%\right)$ and became apparent only when the mismatch exceeded $15 \mathrm{~mm}$.

Long nectar tubes are among the best-known examples of traits functionally involved in pollination, and systems where long-tubed flowers 
are pollinated by long-tongued flies or moths should be prime candidates for predictable covariation between selection and pollinator phenotype (Pauw et al. 2009; and see Week \& Nuismer 2019 for the coevolutionary perspective of flower-pollinator trait matching). Paudel et al. (2016) studied the pollination of the alpine ginger Roscoea purpurea by the long-tongued fly Philoliche longirostris, an example of a specialized interaction with a tight correlation between corolla tube length and fly proboscis length across sites. The flies' proboscises were always shorter than the mean corolla length (as expected in tubular flowers with long tubes; Anderson et al. 2010), yet the authors detected consistent strong positive selection on tube length. The among-site variation $\left(\sigma_{\beta}^{c}\right)$ was only $\sim 40 \%$ of the mean sampling variance in the gradients, suggesting remarkably consistent selection. This lack of variation is perhaps not surprising, because the mismatch between floral and pollinator phenotypes was similar across populations. We can measure the proportional variation in mismatch as the among-site standard deviation of the mismatch (here, proboscis length tube length) scaled against the mean tube length. In this case, the variation in mismatch was around $4 \%$ of the mean tube length. For comparison, the proportional variation in mismatch was $10.6 \%$ in the Caesalpinia study, $19.7 \%$ in the Nicotiana study, and $58.6 \%$ in the Dalechampia study (Appendix 2: Table S1).

\section{Conclusions and outlook}

Through my discussion of pollinator-mediated selection I have argued that a predictive understanding of natural selection requires a combination of (i) functional knowledge of traitperformance-fitness relationships obtained from experiments and detailed observations, (ii) quantitative interpretation of selection estimates, and (iii) explicit consideration of spatiotemporal variation in ecological variables relevant to the focal component of selection. The survey, reanalysis and synthesis of results from the pollination literature yielded several novel insights which jointly suggest that we are now approaching a predictive understanding of the environmental sensitivity of natural selection. First, traits involved in distinct functions (e.g. pollinator attraction vs. flower-pollinator fit) vary both in the mean strength of selection (Fig. 2), in the frequency of cases where spatiotemporal variation exceeds that expected by chance, and in the magnitude of such variation (Fig. 3). Second, a series of studies have confirmed the expected triangular relationship between pollination reliability (population-mean pollination success) and pollinator-mediated selection (Fig. 4). Third, when pollination in less reliable, variation in selection among traits, population and years is often related to variation in the fit of local pollinators to flower phenotypes (Table S1), so that greater variation in misfit seems to be associated with greater variation in selection on relevant traits.

Although much work is still needed to establish their generality, these encouraging results suggest that we can start making predictions about the strength and mode of selection based on simple observations of mean pollination success and the mean phenotypes of plants and their pollinators. A natural next step is to include this mechanistic understanding into evolutionary simulation models assessing the consequences of turnover in biotic communities. One unexplored possibility is to use the accumulated functional knowledge of pollinator-mediated selection to explore the shape of predicted fitness surfaces across ecological contexts, as recently attempted for tree phenology (Gauzere et al. 2020).

This synthesis further highlights several promising approaches for further work. The commonly applied experimental hand-pollination approach to isolating pollinator-mediated selection continues to yield important insights into patterns of pollinator-mediated selection, yet other kinds of experiments are also needed. For example, few studies have combined manipulation of flower function (e.g. manipulation of flower-pollinator fit traits) with estimates of realized selection on the manipulated trait in natural populations (see Ellis \& Johnson 2010). Combining floral manipulation with causal modelling (Fig. 1) could allow understanding the consequences of the trait manipulation on distinct paths linking traits to fitness. Indeed, the methods for causal inference pioneered by Sewall Wright 100 years ago provides a particularly powerful tool for linking data on phenotypic traits, knowledge about traitperformance relationships, and fitness, thus gaining a more complete and predictive 
understanding of the selective process than is possible through the 'standard' multipleregression approach to phenotypic-selection analysis.

Many of the examples of predictable variation in selection on fit traits in response to variation in pollinator assemblages (Appendix 2) concerns rather specialized systems with one or a few functional groups of pollinators (but see Herrera et al. 2006; Gómez et al. 2009). An open question for further work is therefore how predictability vary along gradients of specialization. In systems with multiple functional groups of pollinators, it would be natural to analyse variation in selection as a function of both pollinator functional class and phenotype.

A recurring challenge in studies of pollinatormediated selection is to quantify selection through the male function (Ashman \& Morgan 2004). Direct measures of pollen export requires tracking the fate of pollen through marking of pollen grains (Ellis \& Johnson 2010; Minnaar \& Anderson 2019), pollen analogues such as fluorescent powders (Campbell et al. 1991), or by tracking paternity through genotyping of offspring (Hodgins \& Barrett 2008; Rymer et al. 2010). Due to these logistical challenges, few studies have assessed variation in selection through the male function in more than a few populations, and little is therefore known about the extent of variation in selection through male function, its ecological correlates, and whether the extent of variation in selection differs between the sex functions.

A key insight from the survey of the pollination literature is that defining relevant measures of strength and variation in selection, as well as variation in flower-pollinator fit, can facilitate the interpretation of observed patterns. In particular, the nearly ubiquitous focus in selection studies on variance-standardized selection gradients may have blurred interesting patterns of variation in the strength of selection among trait types, especially when different trait classes differ in variational properties as they do for floral size, flower number, and fit traits. Spatiotemporal variation in selection and flower-pollinator misfit have rarely been quantified, yet recent approaches such as those proposed by Albertsen et al. (2021) for variation in selection, and herein for variation in misfit, are already yielding important novel insights. These and further developments will be critical for moving towards an even more predictive understanding of spatiotemporal variation in natural selection.

\section{ACKNOWLEDGEMENTS}

The ideas presented herein have developed through discussions with Scott Armbruster, Thomas F. Hansen, Christophe Pélabon, Geir H. Bolstad, Rocío PérezBarrales, Elena Albertsen and the Evolutionary Ecology of Plant-Insect Interactions research group at Lund University. I thank Dan Bolnick, Vincent Eckhart, Maria Clara Castellanos and anonymous reviewers for comments that improved the clarity of the text.

\section{APPENDICES}

Additional supporting information may be found in the online version of this article:

Appendix 1. A survey of phenotypic selection on pollination traits

Appendix 2. Examples of studies assessing variation in selection on flower-pollinator fit traits across multiple populations, years, or experimental treatments.

\section{REFERENCES}

Aigner PA (2005) Variation in pollination performance gradients in a Dudleya species complex: can generalization promote floral divergence? Functional Ecology 19:681-689.

Albertsen E, Opedal ØH, Bolstad GH, Perez-Barrales R, Hansen T, Pélabon C, Armbruster WS (2021) Using ecological context to interpret spatiotemporal variation in natural selection. Evolution 75:294-309.

Alexandersson R, Johnson SD (2002) Pollinatormediated selection on flower-tube length in a hawkmoth-pollinated Gladiolus (Iridaceae). Proceedings of the Royal Society B-Biological Sciences 269:631-636.

Anderson B, Johnson SD (2009) Geographical covariation and local convergence of flower depth in a guild of fly-pollinated plants. New Phytologist 182:533-540.

Anderson B, Terblanche JS, Ellis AG (2010) Predictable patterns of trait mismatches between interacting plants and insects. BMC Evolutionary Biology 10:204.

Andersson S (1996) Floral display and pollination success in Senecio jacobaea (Asteraceae): interactive effects of head and corymb size. American Journal of Botany 83:71-75.

Armbruster WS (1988) Multilevel comparative analysis of the morphology, function, and evolution of Dalechampia blossoms. Ecology 69:1746-1761. 
Armbruster WS (1990) Estimating and testing the shapes of adaptive surfaces - the morphology and pollination of Dalechampia blossoms. American Naturalist 135:1431.

Armbruster WS, Antonsen L, Pélabon C (2005) Phenotypic selection on Dalechampia blossoms: honest signaling affects pollination success. Ecology 86:33233333.

Armbruster WS, Gong Y-B, Huang S-Q (2011) Are pollination "syndromes" predictive? Asian Dalechampia fit neotropical models. American Naturalist 178:135-143.

Arnold SJ (1983) Morphology, performance and fitness. American Zoologist 23:347-361.

Arnold SJ, Wade MJ (1984a) On the measurement of natural and sexual selection: applications. Evolution 38:720-734.

Arnold SJ, Wade MJ (1984b) On the measurement of natural and sexual selection: theory. Evolution 38:709719.

Ashman TL, Morgan MT (2004) Explaining phenotypic selection on plant attractive characters: male function, gender balance or ecological context? Proceedings of the Royal Society B-Biological Sciences 271:553-559.

Bartkowska MP, Johnston MO (2012) Pollinators cause stronger selection than herbivores on floral traits in Lobelia cardinalis (Lobeliaceae). New Phytologist 193:1039-1048.

Bartkowska MP, Johnston MO (2015) Pollen limitation and its influence on natural selection through seed set. Journal of Evolutionary Biology 28:2097-2105.

Benkman CW (2013) Biotic interaction strength and the intensity of selection. Ecology Letters 16:1054-1060.

Boberg E, Alexandersson R, Jonsson M, Maad J, Agren J, Nilsson LA (2014) Pollinator shifts and the evolution of spur length in the moth-pollinated orchid Platanthera bifolia. Annals of Botany 113:267-275.

Bodbyl Roels SA, Kelly JK (2011) Rapid evolution caused by pollinator loss in Mimulus guttatus. Evolution 65:2541-2552.

Bolstad GH, Armbruster WS, Pélabon C, Pérez-Barrales R, Hansen TF (2010) Direct selection at the blossom level on floral reward by pollinators in a natural population of Dalechampia schottii: full-disclosure honesty? New Phytologist 188:370-384.

Campbell DR (2009) Using phenotypic manipulations to study multivariate selection of floral trait associations. Annals of Botany 103:1557-1566.

Campbell DR, Forster M, Bischoff M (2014) Selection of trait combinations through bee and fly visitation to flowers of Polemonium foliosissimum. Journal of Evolutionary Biology 27:325-336.
Campbell DR, Powers JM (2015) Natural selection on floral morphology can be influenced by climate. Proceedings of the Royal Society B-Biological Sciences 282:20150178.

Campbell DR, Waser NM, Melendez-Ackerman EJ (1997) Analyzing pollinator-mediated selection in a plant hybrid zone: hummingbird visitation patterns on three spatial scales. American Naturalist 149:295-315.

Campbell DR, Waser NM, Price MV (1996) Mechanisms of hummingbird-mediated selection for flower width in Ipomopsis aggregata. Ecology 77:1463-1472.

Campbell DR, Waser NM, Price MV, Lynch EA, Mitchell RJ (1991) Components of phenotypic selection: pollen export and flower corolla width in Ipomopsis aggregata. Ecology 45:1458-1467.

Caruso CM, Eisen KE, Martin RA, Sletvold N (2019) A meta-analysis of the agents of selection on floral traits. Evolution 73:4-14

Caruso CM, Martin RA, Sletvold N, Morrissey MB, Wade MJ, Augustine KE et al. (2017) What are the environmental determinants of phenotypic selection? A meta-analysis of experimental studies. The American Naturalist 190:363-376.

Castellanos MC, Wilson P, Thomson JD (2004) 'Anti-bee' and 'pro-bird' changes during the evolution of hummingbird pollination in Penstemon flowers. Journal of Evolutionary Biology 17:876-885.

Chapurlat E, Ågren J, Sletvold N (2015) Spatial variation in pollinator-mediated selection on phenology, floral display and spur length in the orchid Gymnadenia conopsea. New Phytologist 208:1264-1275.

Conner JK (1996) Understanding natural selection: an approach integrating selection gradients, multiplicative fitness components, and path analysis. Ethology Ecology \& Evolution 8:387-397.

Conner JK (2003) Artificial selection: a powerful tool for ecologists. Ecology 84:1650-1660.

Cresswell JE (1998) Stabilizing selection and the structural variability of flowers within species. Annals of Botany 81:463-473.

Cresswell JE (2000) Manipulation of female architecture in flowers reveals a narrow optimum for pollen deposition. Ecology 81:3244-3249.

Darwin CR (1862) On the various contrivances by which British and foreign orchids are fertilised by insects, and on the good effects of intercrossing. John Murray, London

De Lisle SP, Svensson EI (2017) On the standardization of fitness and traits in comparative studies of phenotypic selection. Evolution 71:2313-2326.

Eisen KE, Wruck AC, Geber MA (2020) Floral density and co-occurring congeners alter patterns of selection in annual plant communities. Evolution in press. 
Ellis AG, Johnson SD (2010) Gender differences in the effects of floral spur length manipulation on fitness in a hermaphrodite orchid. International Journal of Plant Sciences 171:1010-1019.

Emel SL, Franks SJ, Spigler RB (2017) Phenotypic selection varies with pollination intensity across populations of Sabatia angularis. New Phytologist 215:813-824.

Endler JA (1986) Natural selection in the wild. Princeton Univ. Press, Princeton, NJ

Fenster CB, Armbruster WS, Wilson P, Dudash MR, Thomson JD (2004) Pollination syndromes and floral specialization. Annual Review of Ecology Evolution and Systematics 35:375-403.

Gauzere J, Teuf B, Davi H, Chevin LM, Caignard T, Leys B, Delzon S, Ronce O, Chuine I (2020) Where is the optimum? Predicting the variation of selection along climatic gradients and the adaptive value of plasticity. A case study on tree phenology. Evolution Letters 4:109-123.

Gomez JM, Bosch J, Perfectti F, Fernandez JD, Abdelaziz M, Camacho JP (2008) Spatial variation in selection on corolla shape in a generalist plant is promoted by the preference patterns of its local pollinators. Proc Biol Sci 275:2241-2249.

Gómez JM, Perfectti F, Bosch J, Camacho JPM (2009) A geographic selection mosaic in a generalized plantpollinator-herbivore system. Ecological Monographs 79:245-263.

Grant V, Grant KA (1965) Flower pollination in the Phlox family. Columbia University Press, New York

Hansen V-I, Totland $\varnothing$ (2006) Pollinator visitation, pollen limitation, and selection on flower size through female function in contrasting habitats within a population of Campanula persicifolia. Canadian Journal of Botany 84:412-420.

Harder LD, Johnson SD (2009) Darwin's beautiful contrivances: evolutionary and functional evidence for floral adaptation. New Phytologist 183:530-545.

Hereford J, Hansen TF, Houle D (2004) Comparing strengths of directional selection: how strong is strong? Evolution 58:2133-2143.

Herrera CM, Castellanos MC, Medrano M (2006) Geographical context of floral evolution: towards as improved research programme in floral diversification. In: Harder LD, Barrett SC (eds) Ecology and evolution of flowers. Oxford University Press, Oxford, UK, pp 278-294

Hodgins KA, Barrett SCH (2008) Natural selection on floral traits through male and female function in wild populations of the heterostylous daffodil Narcissus triandrus. Evolution 62:1751-1763.

Johnson SD, Steiner KE (1997) Long-tongued fly pollination and evolution of floral spur length in the
Disa draconis complex (Orchidaceae). Evolution 51:4553.

Kingsolver JG, Hoekstra HE, Hoekstra JM, Berrigan D, Vignieri SN, Hill CE, Hoang A, Gibert P, Beerli P (2001) The strength of phenotypic selection in natural populations. The American Naturalist 157:245-261.

Kingsolver JG, Schemske DW (1991) Path analyses of selection. Trends in Ecology \& Evolution 6:276-280.

Kulbaba MW, Worley AC (2012) Selection on floral design in Polemonium brandegeei (Polemoniaceae): female and male fitness under hawkmoth pollination. Evolution 66:1344-1359.

Kulbaba MW, Worley AC (2013) Selection on Polemonium brandegeei (Polemoniaceae) flowers under hummingbird pollination: in opposition, parallel, or independent of selection by hawkmoths? Evolution 67:2194-2206

La Rosa RJ, Conner JK (2017) Floral function: effects of traits on pollinators, male and female pollination success, and female fitness across three species of milkweeds (Asclepias). American Journal of Botany 104:150-160.

Lande R, Arnold SJ (1983) The measurement of selection on correlated characters. Evolution 37:1210-1226.

Maad J (2000) Phenotypic selection in hawkmothpollinated Platanthera bifolia: targets and fitness surfaces. Evolution 54:112-123.

MacColl AD (2011) The ecological causes of evolution. Trends in Ecology \& Evolution 26:514-522.

Mackin CR, Peña JF, Blanco MA, Balfour NJ, Castellanos MC (2021) Rapid evolution of a floral trait following acquisition of novel pollinators. Journal of Ecology 109:2234-2246.

Matsumura S, Arlinghaus R, Dieckmann U (2012) Standardizing selection strengths to study selection in the wild: a critical comparison and suggestions for the future. Bioscience 62:1039-1054.

Minnaar C, Anderson B (2019) Using quantum dots as pollen labels to track the fates of individual pollen grains. Methods in Ecology and Evolution 10:604-614.

Mitchell RJ (1993) Adaptive significance of Ipomopsis aggregata nectar production: observation and experiment in the field. Evolution 47:25-35.

Mitchell RJ (1994) Effects of floral traits, pollinator visitation, and plant size on Ipomopsis aggregata fruit production. American Naturalist 143:870-889.

Moeller DA, Geber MA (2005) Ecological context of the evolution of self-pollination in Clarkia xantiana: population size, plant communities, and reproductive assurance. Evolution 59:786-799.

Morrissey MB (2016) Meta-analysis of magnitudes, differences and variation in evolutionary parameters. Journal of Evolutionary Biology 29:1882-1904. 
Morrissey MB, Hadfield JD (2012) Directional selection in temporally replicated studies is remarkably consistent. Evolution 66:435-442.

Muchhala N, Thomson JD (2009) Going to great lengths: selection for long corolla tubes in an extremely specialized bat-flower mutualism. Proc Biol Sci 276:2147-2152.

Nattero J, Sérsic AN, Cocucci AA (2010) Patterns of contemporary phenotypic selection and flower integration in the hummingbird-pollinated Nicotiana glauca between populations with different flowerpollinator combinations. Oikos 119:852-863

Nilsson LA (1988) The evolution of flowers with deep corolla tubes. Nature 334:147-149.

Opedal ØН (2019) The evolvability of animal-pollinated flowers: towards predicting adaptation to novel pollinator communities. New Phytologist 221:11281135.

Opedal ØH, Bolstad GH, Hansen TF, Armbruster WS, Pélabon C (2017) The evolvability of herkogamy: quantifying the evolutionary potential of a composite trait. Evolution 71:1572-1586.

Parachnowitsch AL, Caruso CM (2008) Predispersal seed herbivores, not pollinators, exert selection on floral traits via female fitness. Ecology 89:1802-1810.

Parachnowitsch AL, Kessler A (2010) Pollinators exert natural selection on flower size and floral display in Penstemon digitalis. New Phytologist 188:393-402.

Paudel BR, Shrestha M, Burd M, Adhikari S, Sun YS, Li QJ (2016) Coevolutionary elaboration of pollinationrelated traits in an alpine ginger (Roscoea purpurea) and a tabanid fly in the Nepalese Himalayas. New Phytologist 211:1402-1411.

Pauw A, Stofberg J, Waterman RJ (2009) Flies and flowers in Darwin's race. Evolution 63:268-279.

Pérez-Barrales R, Bolstad GH, Pélabon C, Hansen TF, Armbruster WS (2013) Pollinators and seed predators generate conflicting selection on Dalechampia blossoms. Oikos 122:1411-1428.

Rausher MD (1992) The measurement of selection on quantitative traits: biases due to environmental covariances between traits and fitness. Evolution 46:616-626.

Rymer PD, Johnson SD, Savolainen V (2010) Pollinator behaviour and plant speciation: can assortative mating and disruptive selection maintain distinct floral morphs in sympatry? New Phytologist 188:426-436.

Sahli HF, Conner JK (2011) Testing for conflicting and nonadditive selection: floral adaptation to multiple pollinators through male and female fitness. Evolution 65:1457-1473.

Sandring S, Ågren J (2009) Pollinator-mediated selection on floral display and flowering time in the perennial herb Arabidopsis lyrata. Evolution 63:1292-1300.
Scheiner SM, Mitchell RJ, Callahan HS (2000) Using path analysis to measure natural selection. Journal of Evolutionary Biology 13:423-433.

Schemske DW, Horvitz CC (1984) Variation among floral visitors in pollination ability: a precondition for mutualism specialization. Science 225:519-521.

Schemske DW, Horvitz CC (1988) Plant-animal interactions and fruit production in a neotropical herb: a path analysis. Ecology 69:1128-1137.

Schemske DW, Horvitz CC (1989) Temporal variation in selection on a floral character. Evolution 43:461-465.

Shaw RG, Geyer CJ, Wagenius S, Hangelbroek HH, Etterson JR (2008) Unifying life-history analyses for inference of fitness and population growth. American Naturalist 172:E35-47.

Shipley B (2016) Cause and correlation in biology. A user's guide to path analysis, structural equations and causal inference with R. Cambridge University Press, Cambridge

Siepielski AM, DiBattista JD, Carlson SM (2009) It's about time: the temporal dynamics of phenotypic selection in the wild. Ecology Letters 12:1261-1276.

Siepielski AM, Gotanda KM, Morrissey MB, Diamond SE, DiBattista JD, Carlson SM (2013) The spatial patterns of directional phenotypic selection. Ecology Letters 16:1382-1392.

Siepielski AM, Morrissey MB, Buoro M, Carlson SM, Caruso CM, Clegg SM et al. (2017) Precipitation drives global variation in natural selection. Science 355:959 962.

Sletvold N (2019) The context dependence of pollinatormediated selection in natural populations. International Journal of Plant Sciences 180:934-943.

Sletvold N, Ågren J (2010) Pollinator-mediated selection on floral display and spur length in the orchid Gymnadenia conopsea. International Journal of Plant Sciences 171:999-1009.

Sletvold N, Ågren J (2011) Nonadditive effects of floral display and spur length on reproductive success in a deceptive orchid. Ecology 92:2167-2174.

Sletvold N, Ågren J (2014) There is more to pollinatormediated selection than pollen limitation. Evolution 68:1907-1918.

Sletvold N, Ågren J (2016) Experimental reduction in interaction intensity strongly affects biotic selection. Ecology 97:3091-3098.

Soteras F, Rubini Pisano MA, Bariles JB, More M, Cocucci AA (2020) Phenotypic selection mosaic for flower length influenced by geographically varying hawkmoth pollinator proboscis length and abiotic environment. New Phytologist 225:985-998.

Stanton M, Young HJ, Ellstrand NC, Clegg JM (1991) Consequences of floral variation for male and female 
reproduction in experimental populations of wild radish, Raphanus sativus L. Evolution 45:268-280.

Stebbins GL (1974) Flowering plants: evolution above the species level. Belknap Press, Cambridge, MA.

Steiner KE, Whitehead VB (1990) Pollinator adaptation to oil-secreting flowers - Rediviva and Diascia. Evolution 44:1701-1707.

Temeles EJ, Bishop GA (2019) A hurricane alters pollinator relationships and natural selection on an introduced island plant. Biotropica 51:129-138.

Thompson JN (2005) The geographic mosaic of coevolution. The University of Chicago Press, Chicago, US.

Totland $\varnothing$, Andersen HL, Bjelland T, Dahl V, Eide W, Houge $S$ et al. (1998) Variation in pollen limitation among plants and phenotypic selection on floral traits in an early-spring flowering herb. Oikos 82.

Trunschke J, Sletvold N, Ågren J (2017) Interaction intensity and pollinator-mediated selection. New Phytologist 214:1381-1389. van Tienderen PH (2000) Elasticities and the link between demographic and evolutionary dynamics. Ecology 81:666-679.

Vanhoenacker D, Ågren J, Ehrlen J (2013) Non-linear relationship between intensity of plant-animal interactions and selection strength. Ecology Letters 16:198-205.

Wade MJ, Kalisz S (1990) The causes of natural selection. Evolution 44:1947-1955.

Walker JA (2007) A general model of functional constraints on phenotypic evolution. American Naturalist 170:681-689.

Week B, Nuismer SL (2019) The measurement of coevolution in the wild. Ecology Letters 22:717-725.

Wilson P (1995a) Selection for pollination success and the mechanical fit of Impatiens flowers around bumblebee bodies. Biological Journal of the Linnean Society 55:355-383.

Wilson P (1995b) Variation in the intensity of pollination in Drosera tracyi: selection is strongest when resources are intermediate. Evolutionary Ecology 9:382-396. 